\section{$\underset{\substack{\text { hommes } \\ \text { \& migrations }}}{ }$}

\section{Hommes \& migrations}

Revue française de référence sur les dynamiques

migratoires

$1329 \mid 2020$

Migrations et création littéraire

\title{
Nassira El Moaddem, Les filles de Romorantin
}

L'Iconoclaste, Paris, 2019, 208 pages, $17 €$.

\section{Mustapha Harzoune}

\section{OpenEdition}

12 Journals

\section{Édition électronique}

URL : https://journals.openedition.org/hommesmigrations/11297

DOI : 10.4000/hommesmigrations. 11297

ISSN : 2262-3353

Éditeur

Musée national de l'histoire de l'immigration

\section{Édition imprimée}

Date de publication : 1 avril 2020

Pagination : 197-198

ISBN : ISBN 978-2-919040-50-6

ISSN : 1142-852X

Référence électronique

Mustapha Harzoune, "Nassira El Moaddem, Les filles de Romorantin», Hommes \& migrations [En ligne], 1329 | 2020, mis en ligne le 01 avril 2020, consulté le 04 janvier 2023. URL : http://

journals.openedition.org/hommesmigrations/11297; DOI : https://doi.org/10.4000/

hommesmigrations. 11297 


\section{Les filles de Romorantin}

Nassira El Moaddem, Paris, L'Iconoclaste 2019, 208 pages, $17 €$.

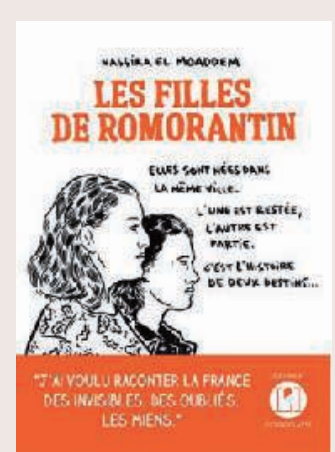

Nassira est journaliste. Nassira est parisienne, installée au centre de la capitale avec mari et progéniture. Nassira est une bourgeoise. Nassira a fait deux grandes écoles, rescapée de ce qu'elle nomme le «tri sélectif» de l'éducation nationale. Nassira est solognote. Romorantin est son «pays, sa terre natale». Mais, à l'heure des premiers entretiens d'embauche, nom, prénom et physique mêlés rappellent moins la tarte Tatin que la semoule et le thé à la menthe chez ses interlocuteurs en retard d'une ou deux sociétés.

La trentaine arrivée, l'auteure se propose de faire un tour, non pas de l'autre côté du périph' - c'est fait - mais du côté de la «France périphérique». Exit les «racailles» des villes, bienvenus aux «bouseux» des champs. «Ma Sologne et les banlieues partageaient bien plus de difficultés communes qu'on ne pouvait l'imaginer. Je le sais, je l'ai vu, vécu.» D'une relégation l'autre. Nassira el Moaddem ferait-elle sa Florence Aubenas? Un peu tout de même, notamment en endossant la blouse de femme de ménage au Center Parc voisin.

En choisissant Romorantin comme terrain d'enquête, l'auteure revisite son enfance. Retour au bercail pour mesurer le chemin parcouru, comparer, interroger la différence de trajectoire, avec cette autre "fille de Romorantin", Caroline, son amie de l'école primaire: "L'une est restée, l'autre est partie.» «Caro est ouvrière, je suis journaliste. J'étais fille d'ouvrier, je suis devenue parisienne de la classe moyenne. Elle était fille de commerçante, elle est devenue ouvrière.»

Mélange des genres: entre reportage avec descriptions des lieux, ambiances et portraits, l'auteure se raconte. Le collectif et l'intime. Elle montre la «tragédie sociale» qui a frappé la ville et ses habitants après la fermeture de l'usine Matra en 2003, les effets de la désindustrialisation et le sentiment de trahison des employés «sacrifiés par Renault et abandonnés par l'État». Aujourd'hui, le territoire est difficile d'accès: sans voiture, on «reste sur le quai»... quand la SNCF ne ferme pas des lignes. Pas étonnant que cette France des Gilets jaunes, par El Moaddem visitée, «vomissent» «les élites». Mais à Saint-Marc, le combat continue. Dans ce quartier des immigrations et des populations «méprisées», les mères se mobilisent pour que la mairie reconstruise l'école. Ah! Monsieur le maire. Jeanny Lorgeoux, socialiste 
passé chez Macron, en marche pour un... septième mandat, en prend pour son grade: consignes données aux employés municipaux de ne pas répondre à la journaliste, désertification du centre-ville qualifié de «nécropole commerciale», amnésie quant au passé ouvrier de la ville... Une descente en flèche. Pourquoi pas? Mais le lecteur, ignorant, attend quelques démonstrations, des témoignages, plutôt qu'un compte rendu univoque de trois heures d'entretien. Comme est expédié, en une formule, le débat sur les cours dispensés dans le cadre des enseignements de langue et de culture d'origine (Elco) - «qui font tant fantasmer les haineux de tous poils »! Circulez, y'a rien à voir! Le prof était peut-être honorable, le système souvent moins... II en est qui n'ont pas attendu que M. Macron se réveille, à Mulhouse, pour en dénoncer les pratiques et les effets.

Caroline et Nassira donc. Caroline renâcle à rencontrer la journaliste - pas besoin d'être «parano» comme l'écrit, un brin corporatiste, l'auteure. Nassira est «passée de l'autre côté des frontières, géographiques et sociales. Avais-je abandonné Caroline, avais-je trahi les miens?» En tout cas, elle ne partage plus le même quotidien: "C'est simple: soit je bouffe à midi, soit je mets l'essence dans ma voiture», dixit Caroline bien sûr.

L'auteure se raconte. De Caroline, on ignore finalement ce qu'elle pense de ces trajectoires «opposées», du regard qu'elle porte sur cette rencontre. C'est justement du côté de l'école que Nassira El Moaddem trouve l'explication: «Pour mon père et ma mère [...] la réussite scolaire était le seul moyen de s'en sortir.» «Nous sommes arrivés là où le déterminisme ne nous attendait pas. Ce désir de revanche sur la vie m'a propulsé loin de Romorantin, et a peut-être fait la différence quand je regarde nos parcours, à Caroline et à moi. Mais j'efface cette pensée au moment de payer l'addition et de nous séparer.»

M. $\mathrm{H}$. 